\title{
Efeitos Regionais da Política Monetária no Brasil: Impactos e Transbordamentos Espaciais
}

\author{
Marinho Bertanha*, Eduardo Amaral Haddad ${ }^{\dagger}$
}

Sumário: 1. Introdução; 2. Metodologia; 3. Estimação; 4. Resultados; 5. Considerações Finais. Palavras-chave: Política Monetária; Economia Regional; SVAR; Econometria Espacial.

Códigos JEL: R15, R50, C32.

Neste artigo propõe-se estimar os impactos da política monetária na atividade dos estados do Brasil, e analisar as diferenças nos efeitos. Baseandose em um modelo Estrutural Espacial de Vetores Auto-Regressivos (SVAR), e utilizando técnicas da econometria espacial, torna-se possível incorporar séries de todos os estados em um mesmo sistema e ainda assim possuir graus de liberdade para a estimação adequada. Testou-se a robustez dos resultados frente à escolha do critério de vizinhança espacial empregado, o que possibilitou estimar e testar a significância dos efeitos de transbordamento dos choques de política monetária entre os estados, tanto contemporaneamente quanto com defasagem.

This paper aims to estimate the impacts of monetary policy on economic activity of the Brazilian states, and to analyze the asymmetry of these effects. Based on a Spatial Structural Vector Auto-Regression (SVAR) model, and using spatial econometrics techniques, our approach makes it possible to include series of every state in just one model and still have degrees of freedom for proper estimation. Robustness of the results facing the choice of spatial weight matrix was tested, which allowed the estimation and testing for significance of contemporaneous as well as lagged spatial spillover effects of monetary policy among states.

\section{INTRODUÇÃO}

O desenvolvimento econômico de um país não necessariamente ocorre de modo homogêneo entre suas regiões. Isso pode levar a sérias disparidades sócio-econômicas dentro de uma mesma nação que

${ }^{*}$ EPGE/FGV e NEREUS/USP. Bolsista da CAPES. E-mail: mbert anha@fgvmail .br.

${ }^{\dagger}$ Departamento de Economia da FEA/USP, NEREUS/USP e REAL/UIUC. Bolsista do CNPq e da Fapesp. E-mail: ehaddad@usp.br. 
não necessariamente possam desvanecer ao longo do tempo pelos mecanismos de alocação presentes no mercado. Tentar diagnosticar essas diferenças bem como formular ações políticas para seu alívio motivou uma farta literatura que constitui uma área da Economia hoje denominada Economia Regional.

Quando se parte para esses estudos, considerar que os efeitos de políticas macroeconômicas como, por exemplo, a política monetária, são uniformes entre as diferentes regiões, pode-se desqualificar todo argumento de motivação dessa área de pesquisa. Além do mais, deixar de levar em conta a dimensão têmporo-espacial de inter-relações entre as unidades espaciais de um país pode levar o pesquisador a atribuir a um determinado fenômeno local causas muitas vezes derivadas do entorno desta unidade. Procuraremos enfatizar a importância destas considerações na medida em que políticas formuladas com base em toda economia e que tragam aparentes benefícios para algumas regiões possam também estar piorando o quadro de disparidades regionais. Eis assim uma motivação para o estudo dos impactos regionais da condução da política monetária. ${ }^{1}$

Há vários estudos sobre efeitos da condução única de política monetária sobre regiões, assunto que tem chamado atenção dos pesquisadores principalmente após a adoção do Euro por um grupo de países europeus. ${ }^{2}$ Para efeitos regionais dentro de um mesmo país, têm-se os trabalhos usando SVAR (Structural Vector Auto-Regression) de Carlino e DeFina (1999), Di Giacinto (2003) para os Estados Unidos; De Lucio e Izquierdo (1999), que também utilizam SVAR para medir os efeitos de políticas monetárias sobre regiões espanholas; e Beenstock e Felsenstein (2005) que apresentam uma abordagem de VAR espacial diferente deste trabalho, aplicando-a para Israel. No caso brasileiro, o problema da falta de dados se torna evidente. Pelo fato das análises existentes serem, em geral, conduzidas com VAR, o sistema de equações consome graus de liberdade rapidamente conforme se aumenta o número de variáveis. Sendo assim, para um estudo que envolva todas as unidades federativas no período pós Plano Real, por exemplo, teríamos de ter séries de produto para cada uma das regiões, com freqüência mensal de modo a possuir número razoável de observações para as estimativas. A escassez de séries temporais com essas características para o Brasil tem forçado os autores a trabalharem com especificações e níveis de agregação regionais diferentes a fim de conseguir graus de liberdade. Isso implica muitas vezes em uma análise baseada em modelos com número insuficiente de defasagens ou também que não incluam todas as unidades espaciais do país dentro de um mesmo modelo estimado.

Dentre os trabalhos elaborados para o Brasil, destacam-se: Fonseca e Vasconcelos (2002), que analisam a influência da taxa SELIC sobre a produção industrial e o crédito bancário nas regiões brasileiras; Chumvichitra (2004), que analisa a relação entre choques monetários e o PIB per capita anual das macroregiões do Brasil; e Araújo (2004), que estima modelos VECM (Vector Error Correction Models) para a série do Índice de Produção Industrial Mensal do IBGE para alguns estados do Nordeste e Sul, e também para o total dessas regiões. Não parece haver padrão claro nos resultados, mesmo quando se comparam estudos que mediram impactos sobre a mesma variável, que no caso seria produção da indústria [Araújo (2004) e Fonseca e Vasconcelos (2002)]. Para os dois estudos com maior abrangência territorial [Fonseca e Vasconcelos (2002) e Chumvichitra (2004)], nota-se, contudo, alguma evidência de que estados do Norte seriam os mais afetados.

Deve-se ressaltar que o fato de não se incluir todas as unidades espaciais de um país no modelo a ser estimado pode enviesar os resultados, o que compromete a análise relativa entre estados.

Um estudo que se abstenha de estudar algumas regiões poderá estar captando como impacto em uma determinada região o efeito de transbordamento do choque de seus vizinhos. Suponha, por exemplo, que os estados da região Sudeste sejam bastante afetados pelo canal juros, já que juntos detêm maior parte da economia nacional. Um estudo que inclua a região Sul, mas não a Sudeste, poderá

\footnotetext{
${ }^{1}$ Outra fonte de interesse para essas investigações, porém advinda já de um nível mais agregado, tem sido observada a partir da adoção de uma moeda única pela União Européia. Tal arranjo institucional chamou a atenção para estudar os efeitos possivelmente assimétricos da condução da política monetária entre os países membros, a chamada literatura sobre áreas monetárias ótimas.

${ }^{2}$ Ver Von Hagen e Waller (2000).
} 
indicar seus estados como fortemente afetados quando na verdade parte do efeito captado advém do efeito de transbordamento espacial da grande economia do Sudeste devido à importância desta região no comércio interestadual.

Neste contexto, propõe-se estimar os impactos da condução da taxa básica de juros (SELIC) no nível de atividade dos estados brasileiros, usando econometria de séries temporais bem como as idéias de contigüidade da econometria espacial. Assim, a principal contribuição do artigo é justamente tratar o sistema inter-regional brasileiro em sua totalidade, captando efeitos associados à interdependência espacial das unidades da Federação, que gera impactos assimétricos de políticas macroeconômicas.

O artigo está estruturado em quatro seções, além desta Introdução. Na Seção 2, apresenta-se a metodologia utilizada no trabalho; a Seção 3 discute os procedimentos de estimação; os resultados são apresentados na Seção 4, seguidos por uma última seção onde são feitas algumas Considerações Finais.

\section{METODOLOGIA}

Um dos objetivos da econometria é averiguar relações propostas pela teoria econômica sobre os mais diversos problemas da área, desde que seja possível quantificá-los e medí-los apropriadamente e se tenha algum registro desses dados. Claramente, em auxílio ao instrumental empregado, hipóteses sobre a realidade serão feitas. Uma delas, crucial em séries temporais e que permitirá desenvolvermos as estimações que seguem, é de que os dados observados em cada período são realizações de variáveis aleatórias ordenadas no tempo que possuem média e variância constantes, e que a correlação entre cada dupla de variáveis depende somente da distância no tempo entre elas. ${ }^{3}$

Até as décadas de 70 e 80 , muito do que fazia e estudava em matéria de macroeconomia e política econômica baseava-se fortemente na estimação de modelos econométricos de larga escala, mais especificamente a metodologia de equações simultâneas. Uma vez que as previsões dessas análises começaram a apresentar falhas, críticas ao método foram surgindo, em especial em Sims (1980). Neste artigo seminal para a macroeconometria, o autor introduz um tipo de modelagem que mais tarde se consagraria no modelo de Vetor Auto-Regressivo (VAR). Vários estudos clássicos sobre política monetária utilizam esse instrumental, por exemplo, Bernanke e Blinder (1992), Bernanke e Mihov (1998), Blanchard e Quah (1989), entre outros. Nesse contexto, tal metodologia apresenta a vantagem de não ser necessário determinar a priori as variáveis endógenas e exógenas no modelo, prática que segundo a crítica de Sims estaria escandalizando os modelos de larga escala, uma vez que para sua estimação seria preciso impor "restrições incríveis para identificação". No VAR, todas as variáveis são consideradas endógenas e permite-se que haja relações entre todas elas e suas defasagens.

Uma das utilidades do VAR é utilizar a dinâmica estimada entre as variáveis para medir o impacto de uma sobre a outra ao longo do tempo. Isto se daria por um choque inesperado (hipótese do ruído branco) no termo de erro de uma equação em um período inicial, o que se transmitiria pelas variáveis nos períodos subseqüentes. No entanto, devido às correlações contemporâneas que possivelmente venham a existir entre os erros, não podemos afirmar que o choque em uma só equação represente um impulso parcial desta variável: se há correlações entre os erros, deveríamos ter movimentos nos erros das outras equações ao mesmo tempo em que um choque artificial é dado na variável em análise.

Desse modo, para uma análise dos efeitos parciais de uma variável sobre as outras, faz-se necessário uma estrutura de modelo que leve em conta estas correlações contemporâneas e possua erros não correlacionados entre equações, os chamados erros na forma estrutural. Entretanto, hipóteses ad hoc sobre as relações simultâneas entre as variáveis precisarão ser feitas para a identificação do modelo. De certa forma, isto nos remete à crítica inicial sobre as restrições para identificação, se bem que agora as relações entre as variáveis nas defasagens são deixadas livres, limitando-se apenas sua simultaneidade. Uma vez em posse do modelo com erros estruturais, um choque sobre uma equação permitirá fazer uma análise parcial das respostas das outras variáveis ao longo do tempo.

\footnotetext{
${ }^{3}$ Trata-se da hipótese de Estacionariedade Fraca, ver Enders (1995, p. 68).
} 
Uma maneira elegante de definir a estrutura dos modelos VAR de modo a atender por estas demandas é através dos modelos SVAR, cuja especificação pode ser usada de várias formas. Amisano e Giannini (1997) tratam dos vários tipos de SVAR e os generalizam no chamado modelo AB. ${ }^{4}$

Neste trabalho, a especificação do modelo empregada refere-se ao SVAR proposto em Di Giacinto (2003) o qual, ao contrário de considerações ad hoc utilizadas em muitos trabalhos empíricos, constrói restrições para identificação utilizando conceitos da econometria espacial. Assim torna-se possível identificar relações contemporâneas entre as variáveis e relações entre os erros estruturais e os da forma reduzida, bem como restringir o grande número de parâmetros de modo a possuir graus de liberdade para a estimação.

\subsection{Relações contemporâneas}

A idéia da dependência espacial entre as regiões advém do fato de que fenômenos que ocorrem nas vizinhanças de uma dada região tendem a influir fortemente na sua atividade econômica através de certos canais de transbordamento. Um deles é o canal do comércio que funciona através dos fluxos de importação e exportação entre os estados, sugerindo que um choque que afete a renda de uma região positivamente tende a aumentar a produção de seus parceiros comerciais. Será tomado este como principal meio para relacionar as unidades federativas espacialmente apesar de que, é de se esperar que outros canais também atuem, como por exemplo, a mobilidade de fatores, de recursos financeiros e de investimentos entre estados.

Como é de praxe em estudos sobre efeitos da política monetária sobre o lado real da economia, as variáveis que serão incluídas no modelo serão: um de índice de preços e um agregado monetário representando a oferta de moeda, sendo que estas duas representam as variáveis de informação do Banco Central (sobrescrito c); variáveis estaduais de emprego como proxies para o nível de atividade econômica (sobrescrito e); e uma taxa de juros, representando o instrumento de política monetária (sobrescrito $i$ ); isso totaliza 30 variáveis no vetor. Esquematicamente,

$$
y_{t}=\left(\begin{array}{c}
I P C_{t} \\
M s_{t} \\
E M P_{1, t} \\
\vdots \\
E M P_{27, t} \\
J U R O S_{t}
\end{array}\right)
$$

Tendo em vista as variáveis que entram no modelo, tem-se abaixo a matriz $A_{0}$ dividida por grupo de variáveis de acordo com os sobrescritos, o que facilita a compreensão das restrições que serão impostas nas relações contemporâneas:

$$
A_{0}=\left(\begin{array}{ccc}
I_{2} & 0 & 0 \\
0 & A_{0}^{e e} & 0 \\
A_{0}^{i c} & A_{0}^{i e} & 1
\end{array}\right)
$$

As relações discorridas, a seguir, referem-se à simultaneidade das variáveis expressas na matriz $A_{0}$, sendo desnecessária a repetição do adjetivo "contemporânea". A partição $I_{2}$ representa uma matriz identidade de ordem 2 o que implica que as variáveis de informação do gestor monetário, inflação e moeda, não são afetadas umas pelas outras, tampouco são afetadas pelas variáveis de emprego e pela taxa de juros. As variáveis de emprego não são afetadas pelas variáveis de informação e nem pela taxa de juros. Entretanto, conforme expresso pela Equação (2), permite-se que o emprego de cada estado afete o emprego nos outros estados.

\footnotetext{
${ }^{4}$ Ver Apêndice.
} 


$$
A_{0}^{e e}=I_{27}-\Phi_{0} \cdot W
$$

onde:

$$
\Phi_{0}=\left(\begin{array}{cccc}
\phi_{0}^{1} & 0 & \cdots & 0 \\
0 & \phi_{0}^{2} & \cdots & 0 \\
\vdots & \vdots & \ddots & \vdots \\
0 & 0 & \cdots & \phi_{0}^{27}
\end{array}\right) W=\left(\begin{array}{cccc}
0 & w_{1,2} & \cdots & w_{1,27} \\
w_{2,1} & 0 & \cdots & w_{2,27} \\
\vdots & \vdots & \ddots & \vdots \\
w_{27,1} & w_{27,2} & \cdots & 0
\end{array}\right)
$$

A matriz diagonal $\Phi_{0}$ é de ordem $27 \times 27$ e contém vinte e sete parâmetros diferentes a serem estimados. A matriz $W$ é a chamada matriz de vizinhança espacial. Com dimensões $27 \times 27$, cada uma de suas linhas informa para um determinado estado, de acordo com algum critério de vizinhança, quem são seus vizinhos no espaço. Os elementos $w_{i j}$ podem ser definidos do seguinte modo:

$$
w_{i j}=\left\{\begin{array}{l}
0, \text { se } i=j \\
0, \text { se } i \neq j \text { e } j \text { não vizinho de } i \\
1, \text { se } i \neq j, j \text { é vizinho de } i
\end{array}\right.
$$

onde $i=1, \ldots, 27$ e $j=1, \ldots, 27$. Pode-se também "normalizar" uma matriz de vizinhança de forma a garantir que a soma de cada linha seja igual a um: $\sum_{j} \mathrm{w}_{i j}=1, i=1, \ldots, 27$. Isso assegura propriedades desejáveis, ${ }^{5}$ além da conveniência de que o produto da matriz por um vetor coluna com 27 variáveis de cada estado, resulta em um vetor coluna com a média dos vizinhos de cada respectivo estado. Um desses critérios de vizinhança, chamado de Queen, caracteriza um estado $j$ como vizinho de um estado $i$ se $j$ tiver fronteira ou nó comum com $i$. Para a normalização, basta dividir os valores unitários de cada linha pelo número de vizinhos do estado da referida linha, procedimento que atribui a cada vizinho um mesmo peso.

Entretanto, tendo em mente a transmissão potencial de choques entre estados via canal de comércio, pode ser reducionista determinar os vizinhos de São Paulo por um critério meramente de contigüidade quando a economia paulista possui grande importância no comércio com a maioria dos estados do Brasil. ${ }^{6}$ Assim, motiva-se a utilização de uma matriz de vizinhança que seja ponderada pelo fluxo de comércio entre os estados. Para tanto, utilizaremos as matrizes de comércio interestadual, para o ano de 1999, estimadas em Vasconcelos e Oliveira (2006). Para cada determinado estado $i$ (linhas) da matriz de vizinhança, somam-se as importações de, e as exportações para, outros estados do país, e calcula-se a participação de cada outro estado $j$ (colunas) nesse montante. Garante-se assim que a matriz seja normalizada e que aqueles "vizinhos" com relações mais fortes de comércio com um estado possuam maior peso do que os outros.

Podemos reescrever a Equação (2) na forma matricial de forma a explicitar seus componentes. Obtém-se:

$$
A_{0}^{e e}=\left(\begin{array}{cccc}
1 & \phi_{0}^{1} \cdot w_{1,2} & \cdots & \phi_{0}^{1} \cdot w_{1,27} \\
\phi_{0}^{2} \cdot w_{2,1} & 1 & \cdots & \phi_{0}^{2} \cdot w_{2,27} \\
\vdots & \vdots & \ddots & \vdots \\
\phi_{0}^{27} \cdot w_{27,1} & \phi_{0}^{27} \cdot w_{27,2} & \cdots & 1
\end{array}\right)_{27 \times 27}
$$

\footnotetext{
${ }^{5}$ Para mais informações a respeito, ver Anselin (1998).

${ }^{6}$ De acordo com Perobelli e Haddad (2006), “de forma hipotética, se não houvesse comércio com o Estado de São Paulo, haveria um maior efeito vizinhança no comércio inter-regional e seus componentes. (...) isso pode indicar o grau de polarização exercido pela economia paulista".
} 
Em outras palavras, esta restrição diz que um estado $i$ depende somente da média do emprego de seus vizinhos, que pode ser a média simples dos vizinhos Queen ou uma média ponderada pelas relações comerciais entre o estado $i$ e outros vinte e seis.

Quanto às outras partições da matriz $A_{0}, A_{0}^{i c}$ expressa a relação do instrumento de política monetária com as variáveis de informação. Trata-se de um vetor linha com duas colunas, em que se permite que a taxa de juros dependa do índice de preços e da moeda. Quanto a $A_{0}^{i e}$, um vetor de uma linha por vinte e sete colunas, exprime-se como a taxa de juros depende dos empregos estaduais. Aqui, os juros dependem apenas do agregado nacional do emprego, proporcionalmente à participação (média no período: vetor coluna $S$ ) de cada estado no total do emprego nacional. Em termos teóricos, essa restrição é motivada pela hipótese de que somente o valor agregado do emprego faz parte do conjunto de informação do Banco Central e, portanto, relevante para a determinação da taxa de juros.

$$
\begin{aligned}
& A_{0}^{i c}=\left(\begin{array}{ll}
a_{0}^{i, c 1} & a_{0}^{i, c 2}
\end{array}\right)_{1 \times 2} \\
& S=\left(\begin{array}{c}
\frac{\sum_{t} \frac{E M P_{1, t}}{E M P_{n a c, t}}}{T} \\
\vdots \\
\frac{\sum_{t} \frac{E M P_{27, t}}{E M P_{n a c, t}}}{T}
\end{array}\right) \\
& A_{0}^{i e}=a_{0}^{i e} \cdot S^{\prime}=\left(\begin{array}{lll}
a_{0}^{i e} \cdot S_{1} & \cdots & a_{0}^{i e} \cdot S_{27}
\end{array}\right)_{1 \times 27}
\end{aligned}
$$

Quando se multiplica o vetor $S$ transposto por um vetor coluna contendo o emprego dos 27 estados, obtém-se uma média ponderada pela importância de cada um destes. A taxa de juros é supostamente relacionada com esta média ao invés de depender diferentemente do emprego de cada estado.

Tendo em vista as restrições acima, podemos agora contá-las e verificar a identificação do modelo. Para as duas variáveis de informação do Banco Central, inflação e moeda, têm-se 60 restrições. Para a variável de emprego, tem-se um parâmetro para cada estado e o resto restrito, portanto, 29 restrições por estado, o que resulta em $29 \times 27=783$ restrições para as equações dos estados. Para a equação dos juros, há 3 parâmetros e 27 restrições. Assim, foram colocadas 870 restrições na matriz $A_{0}$.

Definiremos a matriz $B$ do seguinte modo:

$$
B=\left(\begin{array}{cccc}
\sigma_{1}^{\epsilon} & 0 & \cdots & 0 \\
0 & \sigma_{2}^{\epsilon} & \cdots & 0 \\
\vdots & \vdots & \ddots & \vdots \\
0 & 0 & \cdots & \sigma_{30}^{\epsilon}
\end{array}\right)
$$

onde $\sigma_{i}^{\epsilon}$ são parâmetros correspondentes ao desvio padrão dos erros na forma estrutural, a serem estimados. Impõem-se aqui $\left(n^{2}-n\right)=870$ restrições, totalizando 1740 restrições. A condição necessária requer $2 n^{2}-n(n+1) / 2=1335$ restrições, sendo portanto o sistema sobre-identificado. Dessa forma, o método a ser empregado para a estimação das matrizes $A_{0}$ e $B$ será o de máxima verossimilhança proposto em Amisano e Giannini (1997, p. 20), que assume a distribuição normal dos erros na forma estrutural:

$$
L\left(A_{0}, B\right)=c+\frac{T}{2} \cdot \log \left(\left|A_{0}\right|^{2}\right)-\frac{T}{2} \cdot \log \left(|B|^{2}\right)+\frac{T}{2} \cdot \operatorname{tr}\left(A_{0}^{\prime} B^{\prime-1} B^{-1} A_{0} \hat{\Sigma}\right) \epsilon_{t} \sim N\left(0, I_{30}\right)
$$

Os parâmetros serão resultado do problema de otimização da função acima, o qual faz uso da matriz variância-covariância dos erros na forma reduzida $\hat{\Sigma}$, que deve ser estimada. Assim, é preciso estimar o VAR na forma reduzida numa primeira etapa, obter essa matriz, e então proceder para a segunda etapa 
da estimação do SVAR. Dada a limitação quanto aos graus de liberdade, já discutida, utilizaremos as mesmas restrições empregadas Di Giacinto (2003) para as matrizes dos parâmetros das defasagens na forma reduzida do modelo.

\subsection{Relações defasadas}

Podemos escrever o SVAR na forma reduzida:

$$
\begin{aligned}
A_{0} \cdot y_{t} & =A_{1} \cdot y_{t-1}+\cdots+A_{p} \cdot y_{t-p}+A_{0} \cdot u_{t} \\
y_{t} & =A_{0}^{-1} \cdot A_{1} \cdot y_{t-1}+\cdots+A_{0}^{-1} \cdot A_{p} \cdot y_{t-p}+u_{t} \\
y_{t} & =C_{1} \cdot y_{t-1}+\cdots+C_{p} \cdot y_{t-p}+u_{t}
\end{aligned}
$$

Especificaremos restrições nas matrizes $C_{p}$, ou seja, nas relações entre as defasagens das variáveis que podem ser ilustradas a partir da definição de partições da matriz abaixo:

$$
C_{p}=\left(\begin{array}{ccc}
C_{p}^{c c} & C_{p}^{c e} & C_{p}^{c i} \\
C_{p}^{e c} & C_{p}^{e e} & C_{p}^{e i} \\
C_{p}^{i c} & C_{p}^{i e} & C_{p}^{i i}
\end{array}\right)
$$

onde, como antes, $c$ denota a dupla de variáveis de informação do gestor monetário, $e$ denota as 27 variáveis de emprego, e $i$ a taxa de juros. Não será imposto nenhum tipo de restrição sobre as partições:

- $C_{p}^{c c}(2 \times 2)$ : 4 parâmetros relacionando as variáveis de informação com suas defasagens $p$;

- $C_{p}^{c i}(2 \times 1): 2$ parâmetros relacionando as variáveis de informação com a defasagem $p$ da taxa de juros;

- $C_{p}^{e c}(27 \times 2): 54$ parâmetros relacionando as variáveis de emprego de cada estado com a defasagem $p$ das variáveis de informação;

- $C_{p}^{e i}(27 \times 1): 27$ parâmetros relacionando as variáveis de emprego de cada estado com a defasagem $p$ da taxa de juros;

- $C_{p}^{i c}(1 \times 2): 2$ parâmetros relacionando a taxa de juros com a defasagem $p$ das variáveis de informação;

- $C_{p}^{i i}(1 \times 1): 1$ parâmetro relacionando a taxa de juros com a própria defasagem $p$.

Por outro lado, serão colocadas restrições nas matrizes $C_{p}^{c e}, C_{p}^{e e}$ e $C_{p}^{i e}$ de modo a ter menos parâmetros no modelo e mais de graus de liberdade para a estimação. Estão assim definidas:

$$
C_{p}^{c e}=\alpha_{p}^{c e} \cdot S^{\prime}
$$

onde:

$$
\alpha_{p}^{c e}=\left(\begin{array}{c}
a_{p}^{c 1, e} \\
a_{p}^{c 2, e}
\end{array}\right)
$$

e $S$ é o já conhecido vetor coluna com as participações médias no período do emprego de cada estado no total do país. Reescrevendo (11) na forma matricial, temos:

$$
C_{p}^{c e}=\left(\begin{array}{ccc}
a_{p}^{c 1, e} \cdot S_{1} & \cdots & a_{p}^{c 1, e} \cdot S_{27} \\
a_{p}^{c 2, e} \cdot S_{1} & \cdots & a_{p}^{c 2, e} \cdot S_{27}
\end{array}\right)_{2 \times 27}
$$


Note que o índice de preços ou a moeda dependem apenas da média do emprego defasado em $p$, ponderada pela importância de cada estado. Conformemente, a taxa de juros também depende do mesmo agregado:

$$
\begin{aligned}
C_{p}^{i e} & =a_{p}^{i, e} \cdot S^{\prime} \\
C_{p}^{i e} & =\left(\begin{array}{lll}
a_{p}^{i e} \cdot S_{1} & \cdots & a_{p}^{i e} \cdot S_{27}
\end{array}\right)_{1 \times 27}
\end{aligned}
$$

A variável emprego de cada estado depende da própria defasagem $p$ e da média defasada em $p$ de seus vizinhos, de acordo com a matriz de vizinhança $W$ já discutida acima:

$$
\begin{gathered}
C_{p}^{e e}=\Gamma_{p}+\Phi_{p} \cdot W \\
\Phi_{p}=\left(\begin{array}{cccc}
\phi_{p}^{1} & 0 & \cdots & 0 \\
0 & \phi_{p}^{2} & \cdots & 0 \\
\vdots & \vdots & \ddots & \vdots \\
0 & 0 & \cdots & \phi_{p}^{27}
\end{array}\right) \Gamma_{p}=\left(\begin{array}{cccc}
\gamma_{p}^{1} & 0 & \cdots & 0 \\
0 & \gamma_{p}^{2} & \cdots & 0 \\
\vdots & \vdots & \ddots & \vdots \\
0 & 0 & \cdots & \gamma_{p}^{27}
\end{array}\right)
\end{gathered}
$$

onde (13) pode ser reescrita na forma matricial:

$$
C_{p}^{e e}=\left(\begin{array}{cccc}
\gamma_{p}^{E M P_{1,1}} & \phi_{p}^{1} \cdot w_{1,2} & \cdots & \phi_{p}^{1} \cdot w_{1,27} \\
\phi_{p}^{2} \cdot w_{2,1} & \gamma_{p}^{E M P_{2,2}} & \cdots & \phi_{p}^{2} \cdot w_{2,27} \\
\vdots & \vdots & \ddots & \vdots \\
\phi_{p}^{27} \cdot w_{27,1} & \phi_{p}^{27} \cdot w_{27,2} & \cdots & \gamma_{p}^{E M P_{27,27}}
\end{array}\right)_{27 \times 27}
$$

Percebe-se que nestas três últimas partições, as restrições foram impostas de modo a reduzir o número de parâmetros onde normalmente se teria uma variável dependendo de outras 27 no VAR irrestrito. Estes foram substituídos por apenas um parâmetro relacionando a variável com a média ponderada por um critério de vizinhança espacial ou pela importância do emprego do estado no total. Isso torna possível aumentar o tamanho da cross-section analisada sem diminuir tanto os graus de liberdade. Todavia, as variáveis explicativas em cada equação do VAR não serão mais as mesmas, quando comparadas entre as equações. Seguindo Enders (1995, p. 313), se as equações do VAR diferirem quanto às variáveis explicativas, o método de regressões aparentemente não relacionadas SUR (Seemingly Unrelated Regressions) proporciona estimativas eficientes dos coeficientes do VAR.

\subsection{Transbordamento espacial}

Com o modelo acima especificado, choques na taxa de juros afetam os empregos estaduais e transbordam tanto contemporaneamente quanto com defasagem para os estados vizinhos, o que pode ser esquematizado na Figura 1c abaixo. No estudo de Carlino e DeFina (1999), modela-se o transbordamento espacial apenas com demora de um período, o que pode ser visto na Figura 1b. A Figura 1a mostra um modelo no qual não há possibilidade de transbordamento entre os estados.

Partindo da especificação $c$ em direção a $a$ restringe-se cada vez mais os parâmetros da transmissão espacial dos choques no modelo. Deste modo, pode-se testar a significância estatística desses parâmetros e inferir sobre a presença de transbordamento espacial de cada um dos três tipos acima. Isso poderá ser feito através do teste da razão da verossimilhança (Teste LR). ${ }^{7}$

\footnotetext{
${ }^{7}$ Para o Teste Likelihood Ratio ver Enders (1995, p. 313, p.329) e também Amisano e Giannini (1997, p. 59).
} 
Figura 1 - Especificações de transbordamento espacial

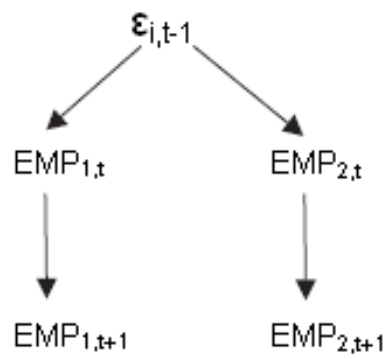

(a)

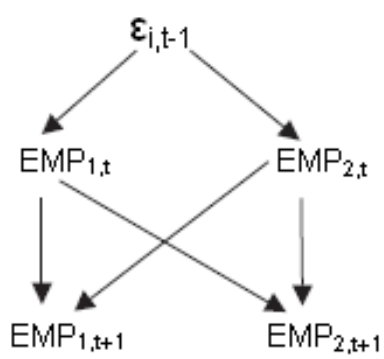

(b)

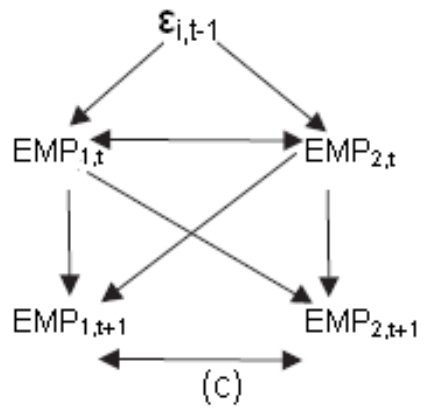

Fonte: Di Giacinto (2003)

Tendo estimado o VAR reduzido, pode-se testar a hipótese nula de que os parâmetros que relacionam o emprego em cada estado com o de seus vizinhos defasados sejam nulos (Figura 1a), e a alternativa de que pelo menos um deles seja diferente de zero (Figura 1b).

$$
H_{0}: \phi_{1}^{1}, \ldots, \phi_{1}^{27}, \ldots, \phi_{p}^{1}, \ldots, \phi_{p}^{27}=0
$$

Seguindo Enders (1995), a estatística do teste para amostras pequenas é:

$$
L R=(T-c) \cdot\left(\log \left|\sum_{r}\right|-\log \left|\sum_{u r}\right|\right) \sim \chi^{2}(r)
$$

onde $T$ é número de observações disponíveis; $\sum_{r} \sum_{u r}$ são as matrizes variância-covariância obtidas, respectivamente, da estimação do modelo estimado sob as restrições de $H_{0}$ e sem nenhuma restrição; $c$, o número de parâmetros estimados em cada equação do modelo irrestrito. Se houver diferença entre elas, como é o caso, deve-se usar o número máximo de variáveis explicativas encontrado entre as equações. A estatística LR possui distribuição Qui-quadrado sob $H_{0}$ com graus de liberdade igual ao número de restrições a serem testadas na hipótese nula, que neste caso é igual ao número $p$ de defasagens no modelo vezes 27 . Caso LR seja maior do que o valor crítico, rejeita-se a hipótese nula e, portanto, há evidências de que haja transbordamento espacial nas $p$ defasagens do modelo.

Uma vez estimado o SVAR e tendo obtido as matrizes $A_{0}$ e $B$, pode-se testar a hipótese nula de que os parâmetros que relacionam contemporaneamente os empregos entre os estados sejam iguais a zero (Figura 1b) contra a alternativa de que pelo menos um deles seja não nulo (Figura 1c).

$$
H_{0}: \phi_{0}^{1}, \ldots, \phi_{0}^{27}=0
$$

Seguindo Amisano e Giannini (1997), podemos escrever a estatística LR em função dos valores máximos da função de verossimilhança calculada para o modelo com as restrições de $H_{0}\left(L_{r}\right)$ e sem nenhuma restrição $\left(L_{u r}\right)$. A distribuição da estatística é a Qui-quadrado sob $H_{0}$, com graus de liberdade igual ao número de restrições a serem testadas na hipótese nula, que neste caso é 27.

$$
L R=2 \cdot\left(L_{u r}-L_{r}\right) \sim \chi^{2}(r)
$$

Caso LR seja maior do que o valor crítico, rejeita-se a hipótese nula e, portanto, há evidências de que haja transbordamento espacial contemporâneo no modelo. 


\subsection{Função de resposta a impulso}

Conforme foi explicado inicialmente, uma das funções da metodologia de vetores auto-regressivos é utilizar o sistema dinâmico estimado para estudar efeitos de choques no termo de erro de uma determinada variável sobre o restante delas ao longo do tempo. A representação gráfica destes impactos é dita Função de Resposta a Impulso (FRI). Sendo assim, este trabalho estimará as FRI para o emprego de cada um dos 27 estados dado um choque na taxa de juros. Para derivar essas funções, podemos reescrever a equação matricial do VAR em forma de VMA (Vector Moving Average), isto é, expressando o vetor de variáveis $y_{t}$ em função dos erros na forma estrutural. Sabendo-se de que $A_{0} \cdot u_{t}=B \cdot \epsilon_{t}$ e $L^{k} y_{t}=y_{t-k}$ :

$$
\begin{aligned}
& y_{t}-C_{1} \cdot y_{t-1}-\cdots-C_{p} \cdot y_{t-p}=u_{t} \\
& A_{0} \cdot\left(y_{t}-C_{1} \cdot y_{t-1}-\cdots-C_{p} \cdot y_{t-p}\right)=A_{0} \cdot u_{t} \\
& A_{0} \cdot\left(y_{t}-C_{1} \cdot L^{1} \cdot y_{t}-\cdots-C_{p} \cdot L^{p} \cdot y_{t}\right)=A_{0} \cdot u_{t} \\
& A_{0} \cdot C(L) \cdot y_{t}=B \cdot \epsilon_{t} \\
& y_{t}=C(L)^{-1} \cdot A_{0}^{-1} \cdot B \cdot \epsilon_{t} \\
& y_{t}=P(L) \cdot \epsilon_{t}
\end{aligned}
$$

onde o $P(L)$ é um polinômio no operador $L$, com as matrizes quadradas $P_{p}$ de ordem 30 tal que:

$$
y_{t}=P_{o} \cdot \epsilon_{t}+P_{1} \cdot \epsilon_{t-1}+P_{2} \cdot \epsilon_{t-2}+\cdots
$$

Desse modo, para saber como um choque em $\epsilon_{1, t}$ afeta $y_{1, t}$, basta observar o elemento na primeira linha e primeira coluna de $P_{0}$. Este será o impacto simultâneo do choque, sendo que para se ter os impactos nos períodos posteriores, deve-se observar o mesmo elemento nas matrizes $P_{1}, P_{2}, P_{3} \ldots \mathrm{A}$ FRI será o gráfico resultante desses valores ao longo do tempo. Note que se pode repetir este exercício usando várias combinações de variáveis nas quais é dado o impulso e nas quais se observa a resposta. Em termos de inferência, Amisano e Giannini (1997, p. 65) derivam a fórmula para o desvio-padrão desses valores, e sabendo-se que possuem distribuição assintótica normal, é possível construir intervalos de confiança para as FRI. Assim, pode-se inferir quais impactos são estatisticamente diferentes de zero.

\section{ESTIMAÇÃO}

\subsection{Dados}

A amostra utilizada neste estudo contém dados de freqüência mensal, e refere-se ao período entre Janeiro de 1995 a Dezembro de 2005, portanto, com 132 observações. A medida de preços escolhida foi o Índice de Preços ao Consumidor Amplo (IPCA) para o Brasil fornecido pelo IBGE, variação percentual mensal, por assim ser grande referencial para a inflação de consumo além de ser alvo das metas da condução da política monetária. Para a variável moeda, utilizou-se a série dos meios de pagamento M1, média dos dias úteis do mês em valores correntes, disponível no sítio do Banco Central. A taxa de juros escolhida foi a SELIC efetiva em termos mensais. As séries estaduais com freqüência mensal não estão diretamente disponíveis e tiveram de ser construídas com base nas informações para o emprego CLT disponíveis nas bases RAIS e CAGED, fornecidas pelo Ministério de Trabalho e Emprego. Para testarmos a robustez dos resultados quanto à escolha da matriz de vizinhança espacial, bem como inferir algumas conclusões sobre o transbordamento espacial, três modelos serão estimados:

(i) o modelo comércio, que utiliza a matriz de vizinhança espacial construída a partir do volume transacionado entre os estados;

(ii) o modelo queen; 
(iii) e o modelo sem transbordamento, em que a matriz de vizinhança é nula.

\subsection{Etapas da estimação}

Conforme exposto na seção anterior, foram adotados os seguintes passos de estimação para se chegar às FRI e, portanto, nos impactos do aumento dos juros sobre o emprego nos estados:

a) Teste de raiz unitária das variáveis;

b) Estimação da VAR na forma reduzida por SUR;

c) Determinação do número de defasagens no VAR;

d) Teste da significância do transbordamento espacial nas defasagens;

e) Estimação do SVAR por Máxima-Verossimilhança;

f) Teste da significância do transbordamento espacial contemporâneo;

g) Cálculo das FRI, e seus intervalos de confiança.

Para inferir sobre a estacionariedade das séries, empregou-se o teste Aumentado de Dickey-Fuller (ADF). ${ }^{8}$ As séries testadas são das variáveis mencionadas acima, sendo que para $\mathrm{M} 1$ e as de emprego, tomou-se o logaritmo natural em cada caso a fim de estabilizar suas variâncias. O procedimento geral adotado para o teste ADF consiste em começar estimando o modelo completo, isto é, com constante e tendência cujas significâncias serão avaliadas. Em seguida, ajusta-se o número de defasagens de modo a corroborar a hipótese de ruído branco para os erros. Por fim, testa-se a hipótese nula de uma raiz unitária. Os resultados dos testes se encontram na Tabela 1. Não se rejeita a hipótese de uma raiz unitária a $1 \%$ para a série de $\mathrm{M} 1$ e para as séries de emprego de todos os estados. As variáveis IPCA e SELIC são estacionárias a 1\%. Utilizou-se a primeira-diferença daquelas séries que apresentaram evidências de uma raiz unitária.

A recomendação usual é de que as variáveis usadas no VAR sejam estacionárias. De acordo com Matsumoto (2000), uma das alternativas sugeridas pela literatura que trata sobre transmissão de política monetária consiste em utilizar as séries em primeira-diferença caso não sejam estacionárias. Por outro lado, perdem-se as possíveis inter-relações de longo prazo entre as variáveis. A alternativa seria testar se há relações de co-integração entre as variáveis e, caso haja, utilizar o modelo VECM, que gera estimativas eficientes sem perda das informações de longo prazo das séries. Entretanto, caso não se tenha nenhuma informação a priori sobre a relação de longo prazo esperada, algo difícil num modelo com tantas variáveis como aqui é o caso, impor esse ou aquele vetor de co-integração poderá gerar estimativas tendenciosas. Além do mais, o objetivo deste estudo é medir os impactos da política monetária sobre a economia apenas no curto prazo, sendo que a argumentar sobre a persistência no longo prazo de choques monetários sobre o lado real da economia pode ser controverso.

Como discutido anteriormente, estimou-se o VAR pelo método SUR, para cada um dos dois tipos de matriz de vizinhança espacial. Para a escolha do número de defasagens, empregaram-se os critérios de informação de Akaike e Schwarz, além do teste da razão da verossimilhança. Além disso, também se averiguaram os correlogramas dos resíduos das equações de cada um dos modelos para várias opções de defasagens, de modo a verificar a concordância com a hipótese de ruído branco.

\footnotetext{
${ }^{8}$ Ver Vasconcellos e Alves (1999, p. 245) para o detalhamento dos procedimentos e critérios aqui empregados.
} 
Tabela 1 - Teste ADF

\begin{tabular}{cccc}
\hline Variável & Modelo & Defasagens & Estatística \\
\hline IPCA & cte & 7 & -3.97 \\
SELIC & cte & 6 & -4.05 \\
M1 & nada & 12 & $2.00^{* *}$ \\
\hline RO & tend+cte & 4 & $-2.96^{* *}$ \\
AC & nada & 12 & $5.18^{* *}$ \\
AM & tend+cte & 12 & $-2.07^{* *}$ \\
RR & tend+cte & 12 & $-2.87^{* *}$ \\
PA & nada & 12 & $2.07^{* *}$ \\
AP & tend+cte & 7 & $-3.24^{* *}$ \\
TO & nada & 11 & $1.72^{* *}$ \\
MA & nada & 12 & $1.54^{* *}$ \\
PI & nada & 1 & $3.29^{* *}$ \\
CE & tend+cte & 12 & $-2.73^{* *}$ \\
RN & nada & 11 & $2.28^{* *}$ \\
PB & nada & 12 & $1.61^{* *}$ \\
PE & tend+cte & 12 & $-1.28^{* *}$ \\
AL & nada & 12 & $0.69^{* *}$ \\
SE & tend+cte & 12 & $-3.73^{*}$ \\
BA & tend+cte & 12 & $-2.44^{* *}$ \\
MG & nada & 12 & $1.47^{* *}$ \\
ES & nada & 12 & $1.09^{* *}$ \\
RJ & nada & 12 & $1.12^{* *}$ \\
SP & nada & 12 & $1.16^{* *}$ \\
PR & tend+cte & 12 & $-2.73^{* *}$ \\
SC & nada & 12 & $2.11^{* *}$ \\
RS & tend $+c t e$ & 12 & $-3.15^{* *}$ \\
MS & nada & 12 & $1.11^{* *}$ \\
MT & nada & 12 & $0.65^{* *}$ \\
GO & tend+cte & 12 & $-3.79^{*}$ \\
DF & tend $+c t e$ & 12 & $-2.71^{* *}$ \\
\hline 1 & 12 &
\end{tabular}

* - 1 RU a $1 \%$ de signficância.

** -1 RU a 5\% de signficância.

Para o modelo comércio, inicialmente testou-se a hipótese nula (14) de que os parâmetros que relacionam espacialmente as variáveis de emprego são iguais a zero contra a hipótese alternativa de que pelo menos algum deles seja relevante. Como não se pôde rejeitar essa hipótese, dado o alto $p$-valor, suspeitou-se de que poderia haver transbordamento espacial em um número menor de defasagens. Para isso, realizaram-se outros oito testes de hipótese, nos quais se testava a hipótese nula de que os parâmetros que relacionam espacialmente as variáveis de emprego são iguais a zero em oito das nove defasagens; em sete das nove defasagens; em seis das nove defasagens; e assim por diante; contra a hipótese alternativa de que pelo menos algum deles seja relevante. Os resultados são mostrados na Tabela 2a e revelam que é possível rejeitar a hipótese nula para o caso de que haja transmissão espacial somente na primeira defasagem. Entretanto, para o modelo queen (Tabela $2 \mathrm{~b}$ ) já de início se rejeita a hipótese nula que não haja transmissão espacial defasada, conjuntamente para as nove defasagens. Esta diferença quanto aos resultados dos testes pode sugerir que quando se utiliza a matriz de vizinhança do tipo queen e, portanto, se abstraem inter-relações econômicas entre dois estados que aparecem na 
matriz do comércio, o transbordamento espacial persiste por mais períodos do que no caso do comércio. Neste último, como se utiliza um dado de integração econômica entre os estados para o critério de vizinhança, choques numa economia estadual demoram no máximo um mês para se transmitirem aos seus vizinhos. Os parâmetros do transbordamento que aqui se mostraram insignificantes foram excluídos da especificação do VAR.

Tabela 2 - Teste LR - Transbordamento nas defasagens

\begin{tabular}{ccccc}
\hline \multicolumn{6}{l}{ (a) Modelo Comércio } & & & \\
\hline Defasagem & OBS & Restrições a testar & LR & $P$-valor \\
\hline 9 & 123 & 243 & 192,07 & $99,3 \%$ \\
8 & 123 & 216 & 164,91 & $99,6 \%$ \\
7 & 123 & 189 & 147,99 & $98,8 \%$ \\
6 & 123 & 162 & 132,90 & $95,4 \%$ \\
5 & 123 & 135 & 116,67 & $87,1 \%$ \\
4 & 123 & 108 & 107,40 & $49,8 \%$ \\
3 & 123 & 81 & 82,90 & $42,1 \%$ \\
2 & 123 & 54 & 60,88 & $24,2 \%$ \\
1 & 123 & 27 & 42,09 & $3,2 \%$ \\
\hline (b) Modelo Queen & & & \\
9 & 123 & 243 & 327,09 & $0,03 \%$ \\
\hline
\end{tabular}

Uma vez estimados os modelos na forma reduzida, procede-se para a maximização da função de verossimilhança descrita anteriormente, o que dará as estimativas dos parâmetros das matrizes $A_{0}$ e $B$, bem como seus desvios-padrão e covariâncias. Conforme explicado acima, para o 'modelo sem transbordamento', as estimativas foram obtidas restringindo-se os parâmetros como sendo iguais a zero. Para os outros dois modelos, testou-se a hipótese nula (15) de que esses parâmetros sejam iguais a zero, empregando-se o teste LR (15') acima discutido. Os resultados estão não na Tabela 3 para os modelos comércio e queen.

Tabela 3 - Teste LR - Transbordamento contemporâneo

\begin{tabular}{cccc}
\hline Modelo & Restrições a Testar & LR & $P$-valor \\
\hline Comércio & 27 & 578,07 & $0,0000 \%$ \\
Queen & 27 & 448,03 & $0,0000 \%$ \\
\hline
\end{tabular}

Note que para ambas as especificações, comércio e queen, rejeita-se a hipótese nula de que não há transbordamento contemporâneo, o que, juntamente com os resultados positivos do transbordamento defasado da seção anterior, revela a importância de se considerar no modelo esses efeitos espaciais.

\section{RESULTADOS}

\subsection{Impactos sobre os estados}

Levando em conta o fato de que os valores estimados na FRI se referem aos impactos sobre a taxa de variação percentual mensal do emprego nos estados, números estes que podem ser de difícil interpretação, a análise dos resultados que aqui se fará será baseada em uma simulação de impacto sobre um 
cenário base. ${ }^{9}$ Em outros termos, sobre as variações percentuais dos últimos seis meses da série (Jul-05 a Dez-05), aplicam-se os impactos estimados pela FRI, somente aqueles estatisticamente diferentes de zero, e calculam-se os níveis de emprego resultantes dessas novas taxas. O valor que se obtém para dezembro de 2005 neste cenário de impacto se refere ao nível de emprego estimado que se teria caso a autoridade monetária tivesse aumentado a taxa SELIC de forma inesperada no mês de julho de 2005. Note que o choque na taxa de juros ocorre somente no mês de julho, sendo que a trajetória da SELIC a partir de então será dada pela dinâmica estimada do modelo. Os valores foram calculados para um aumento de um ponto percentual em termos anuais na taxa em julho.

Para efeitos de comparação entre os estados, calculou-se a diferença entre o nível de emprego no cenário de impacto e no cenário base como proporção do nível de emprego no cenário base, obtendo-se portanto o impacto acumulado em 6 meses em termos relativos. A Tabela 4 mostra esses impactos em cada estado, já ordenados do valor mais negativo para o menos, de acordo com os resultados do modelo comércio. Cabe ressaltar que o ordenamento dos estados não se altera pelo fato de se trabalhar com impacto relativo calculado na simulação feita ao invés de simplesmente somar os impactos sobre a variação percentual no emprego, conforme estimado nas FRI. A parte (a) mostra os resultados para o modelo comércio; a parte (b) para o modelo queen; e a (c) mostra a diferença entre a posição de cada estado nos dois ordenamentos, isto é, a posição no ordenamento (a) subtraída da posição no ordenamento (b). Se esta variação for positiva, isto significa que ao se trocar a matriz de vizinhança de comércio para queen, determinado estado perdeu posição no ordenamento, e vice-versa. De maneira geral, observa-se que os estados do Norte e Nordeste são os que têm seus empregos mais afetados pelo aumento dos juros. Nota-se que os seis primeiros estados, Tocantins, Amapá, Acre, Distrito Federal, Piauí e Roraima, bem como outros mais abaixo, Goiás, Rio de Janeiro e Paraná, não mudam de posição no ordenamento com a troca da matriz de vizinhança, mostrando a robustez dos resultados. Um resultado talvez contra-intuitivo seja os dos estados que sofrem um impacto positivo sobre o emprego com o aumento dos juros.

A Tabela 5 compara os impactos estimados através do modelo comércio (a) com os impactos do modelo sem transbordamento (b). A variação na posição dos estados também é mostrada na parte (c). Novamente temos a permanência dos estados mais afetados no topo da lista além do fato de que Paraná, Alagoas e Rondônia continuam com impactos positivos e no fim da lista, trocando apenas entre si suas posições. É interessante notar como São Paulo sobe de posição bruscamente quando se tira o transbordamento do modelo. Outro que também faz o mesmo movimento é o Estado do Amazonas, talvez por ali se localizar a Zona Franca de Manaus que possui importante fluxo de comércio com o restante do país.

\footnotetext{
${ }^{9}$ As Funções Resposta a Impulso, calculadas a partir do modelo comércio, encontram-se no Apêndice.
} 
Tabela 4 - Impactos do aumento da taxa SELIC: 'Comércio' e 'queen'

\begin{tabular}{cc|cc|cc}
\hline \multicolumn{2}{c}{ (a) Comércio } & \multicolumn{3}{c}{ (b) Queen } & \multicolumn{2}{c}{ (c) Variação } \\
\hline Estado & Impacto relativo & Estado & Impacto relativo & Estado & $\Delta$ Posição \\
\hline TO & $-0,1942 \%$ & TO & $-0,2657 \%$ & TO & 0 \\
AP & $-0,1635 \%$ & AP & $-0,1852 \%$ & AP & 0 \\
AC & $-0,1521 \%$ & AC & $-0,1654 \%$ & AC & 0 \\
DF & $-0,1251 \%$ & DF & $-0,1363 \%$ & DF & 0 \\
PI & $-0,1065 \%$ & PI & $-0,1095 \%$ & PI & 0 \\
RR & $-0,0948 \%$ & RR & $-0,1002 \%$ & RR & 0 \\
ES & $-0,0892 \%$ & ES & $-0,0952 \%$ & ES & 1 \\
SC & $-0,0764 \%$ & SC & $-0,0987 \%$ & SC & -1 \\
SE & $-0,0653 \%$ & SE & $-0,0775 \%$ & SE & 2 \\
RN & $-0,0600 \%$ & RN & $-0,0896 \%$ & RN & -1 \\
AM & $-0,0598 \%$ & AM & $-0,0650 \%$ & AM & 1 \\
BA & $-0,0592 \%$ & BA & $-0,0870 \%$ & BA & -2 \\
RS & $-0,0524 \%$ & RS & $-0,0360 \%$ & RS & 3 \\
MG & $-0,0492 \%$ & MG & $-0,0275 \%$ & MG & 3 \\
PB & $-0,0484 \%$ & PB & $-0,0541 \%$ & PB & -1 \\
SP & $-0,0429 \%$ & SP & $-0,0429 \%$ & SP & -1 \\
CE & $-0,0302 \%$ & CE & $-0,0618 \%$ & CE & -4 \\
GO & $-0,0286 \%$ & GO & $-0,0272 \%$ & GO & 0 \\
PA & $-0,0285 \%$ & PA & $-0,0209 \%$ & PA & 2 \\
RJ & $-0,0260 \%$ & RJ & $-0,0232 \%$ & RJ & 0 \\
MT & $-0,0122 \%$ & MT & $0,0055 \%$ & MT & 3 \\
MS & $0,0013 \%$ & MS & $0,0037 \%$ & MS & 1 \\
MA & $0,0023 \%$ & MA & $-0,0245 \%$ & MA & -4 \\
PE & $0,0086 \%$ & PE & $-0,0040 \%$ & PE & -2 \\
PR & $0,0165 \%$ & PR & $0,0141 \%$ & PR & 0 \\
AL & $0,0700 \%$ & AL & $0,0411 \%$ & AL & 1 \\
RO & $0,0717 \%$ & RO & $0,0205 \%$ & RO & -1 \\
\hline & & & & & \\
\hline
\end{tabular}


Tabela 5 - Impactos do aumento da taxa SELIC: 'Comércio' e 'sem transbordamento’

\begin{tabular}{cc|cc|cc}
\hline \multicolumn{2}{c}{ (a) Comércio } & \multicolumn{2}{c}{ (b) sem transbordamento } & \multicolumn{2}{c}{ (c) Variação } \\
\hline Estado & Impacto relativo & Estado & Impacto relativo & Estado & $\Delta$ Posição \\
\hline TO & $-0,1942 \%$ & TO & $-0,3300 \%$ & TO & 0 \\
AP & $-0,1635 \%$ & AP & $-0,1775 \%$ & AP & 0 \\
AC & $-0,1521 \%$ & AC & $-0,1473 \%$ & AC & 0 \\
DF & $-0,1251 \%$ & DF & $-0,1351 \%$ & DF & 0 \\
PI & $-0,1065 \%$ & PI & $-0,1141 \%$ & PI & 2 \\
RR & $-0,0948 \%$ & RR & $-0,0945 \%$ & RR & 4 \\
ES & $-0,0892 \%$ & ES & $-0,1070 \%$ & ES & 1 \\
SC & $-0,0764 \%$ & SC & $-0,0748 \%$ & SC & 5 \\
SE & $-0,0653 \%$ & SE & $-0,0827 \%$ & SE & 0 \\
RN & $-0,0600 \%$ & RN & $-0,1115 \%$ & RN & -1 \\
AM & $-0,0598 \%$ & AM & $-0,1274 \%$ & AM & -6 \\
BA & $-0,0592 \%$ & BA & $-0,0632 \%$ & BA & 5 \\
RS & $-0,0524 \%$ & RS & $-0,0425 \%$ & RS & 3 \\
MG & $-0,0492 \%$ & MG & $-0,0600 \%$ & MG & 0 \\
PB & $-0,0484 \%$ & PB & $-0,0628 \%$ & PB & 2 \\
SP & $-0,0429 \%$ & SP & $-0,1281 \%$ & SP & -10 \\
CE & $-0,0302 \%$ & CE & $-0,0658 \%$ & CE & 1 \\
GO & $-0,0286 \%$ & GO & $-0,0673 \%$ & GO & -5 \\
PA & $-0,0285 \%$ & PA & $-0,0327 \%$ & PA & 0 \\
RJ & $-0,0260 \%$ & RJ & $-0,0305 \%$ & RJ & 2 \\
MT & $-0,0122 \%$ & MT & $-0,0110 \%$ & MT & -1 \\
MS & $0,0013 \%$ & MS & $-0,0072 \%$ & MS & 1 \\
MA & $0,0023 \%$ & MA & $-0,0419 \%$ & MA & 1 \\
PE & $0,0086 \%$ & PE & $-0,0502 \%$ & PE & -4 \\
PR & $0,0165 \%$ & PR & $0,0103 \%$ & PR & 0 \\
AL & $0,0700 \%$ & AL & $0,0143 \%$ & AL & -1 \\
RO & $0,0717 \%$ & RO & $0,0220 \%$ & RO & 1 \\
\hline & & & & &
\end{tabular}

Resumidamente, calculou-se a média dos impactos relativos, o desvio-padrão e número de empregos perdidos no país com o aumento dos juros para cada uma das três especificações. Essas medidas resumo se encontram na Tabela 6.

Tabela 6 - Medidas resumo dos impactos nos três modelos

\begin{tabular}{c|cccc}
\hline & Impactos & Comércio & Queen & Sem transbordamento \\
\hline Média & Relativos & $-0,0516 \%$ & $-0,0634 \%$ & $-0,0785 \%$ \\
Desvio-padrão & & $0,0619 \%$ & $0,0678 \%$ & $0,0706 \%$ \\
\hline Total BR & Absolutos & -10182 & -10493 & -19494 \\
\hline
\end{tabular}

Pelos valores acima, nota-se que à medida que se tira a espacialidade do modelo, indo do 'comércio' para 'sem transbordamento', os impactos da política monetária vão ficando em média mais fortes e mais dispersos. Além disso, o impacto nacional sobre o número de empregos, conforme simulação para o segundo semestre de 2005, também aumenta, quase dobrando. Para uma possível interpretação, é preciso primeiro pensar que os dados de emprego observados no mundo real devem refletir algum tipo de transbordamento espacial, seja ele melhor representado pelos fluxos comerciais ou não. A questão 
é como isso será controlado na estimação do modelo. Quando se aumentam os juros, a economia de um estado é afetada diretamente pela taxa mais alta e indiretamente pelo impacto negativo de seus vizinhos. O impacto negativo nos vizinhos pode vir diretamente dos juros em suas economias e indiretamente de seus vizinhos e assim por diante, em um encadeamento por todos os estados do país, que pode ocorrer durante o mesmo mês, ou demorar mais meses. Quando se tem um modelo que não leva em conta o transbordamento, na hora da estimação, não se controla pelo emprego dos vizinhos quando se mede o impacto dos juros sobre um estado, coisa que é feita no modelo com transbordamento. Um impacto pode ser estimado como grande e significante quando advindo só de dentro de um estado, mas quando se permite sua geração por muitos vizinhos, ele poderá ser dividido em impactos menores, talvez alguns sendo insignificantes. Como na simulação feita acima foram considerados somente aqueles impactos estatisticamente diferentes de zero, isso explicaria os menores efeitos totais no modelo com transbordamento.

A Figura 2 traz o mapa do Brasil onde se ilustram espacialmente os impactos relativos, estimados pelo modelo comércio. As cores mais escuras representam os efeitos mais negativos e vice-versa, e os números destacados em cada estado representam a diferença no nível de emprego entre o cenário base e de impacto.

Percebe-se que em termos absolutos São Paulo, Minas Gerais, e Santa Catarina são os estados que mais perdem empregos com o aumento dos juros. Abaixo na Figura 3, calculou-se o quanto se ganha em termos de impacto relativo dos juros sobre emprego, quando se controla pelo transbordamento espacial no modelo comércio. Quanto mais escuras as cores, maior ganho em termos relativos. Os números do mapa representam o montante de empregos que o estado deixa de perder quando há transbordamento pelo comércio no modelo. Nota-se que São Paulo, segundo diferença nas estimativas dos dois modelos, deixa de perder 7060 empregos quando há controle espacial pela matriz do comércio. Além disso, levar em conta as inter-relações comerciais entre os estados traz ganhos para 20 das 27 unidades federativas do Brasil.

Por último, para visualizar os transbordamentos do emprego entre os estados, construiu-se um gráfico tridimensional a partir das FRI obtidas, estimando-se o impacto sobre um estado como resposta a um choque em outro estado. Na Figura 4, abaixo, o eixo $z$ dos valores representa os impactos acumulados em 6 meses sobre o emprego, e os outros eixos representam: o estado cujo emprego recebeu um choque e o estado onde se mede a resposta. Os choques que foram dados nos estados correspondem aos impactos estatisticamente diferentes de zero da taxa de juros sobre o emprego. As partes da Figura 4 correspondem aos resultados dos modelos (a) comércio, (b) queen, e (c) sem transbordamento. Na Figura $4 \mathrm{a}$ é interessante ressaltar o repasse que o estado de São Paulo faz à grande maioria dos estados brasileiros do impacto dos juros sobre o seu nível de emprego. 
Figura 2 - Impactos relativos e absolutos sobre o emprego estadual

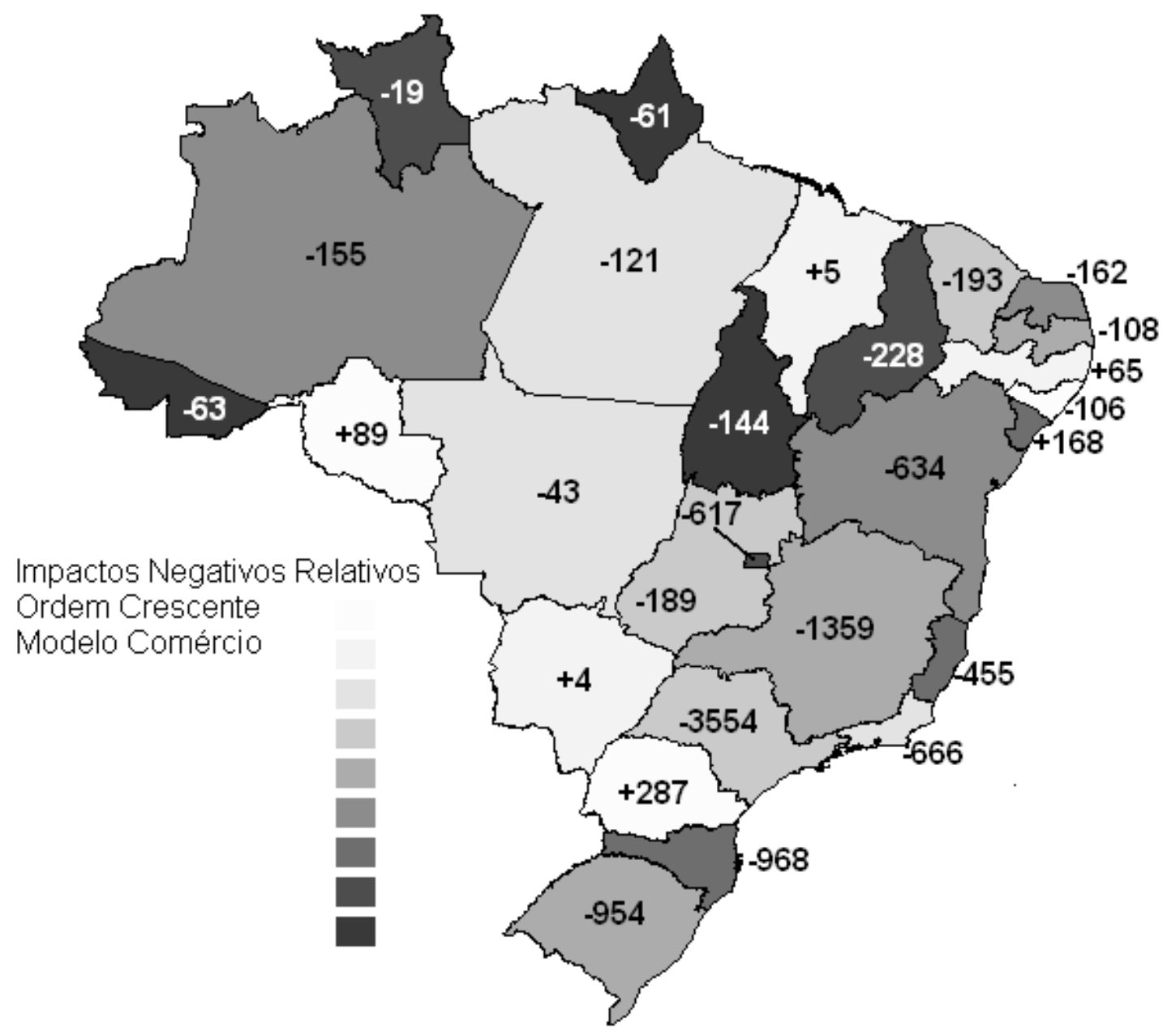


Figura 3 - Ganhos relativos e absolutos com transbordamento

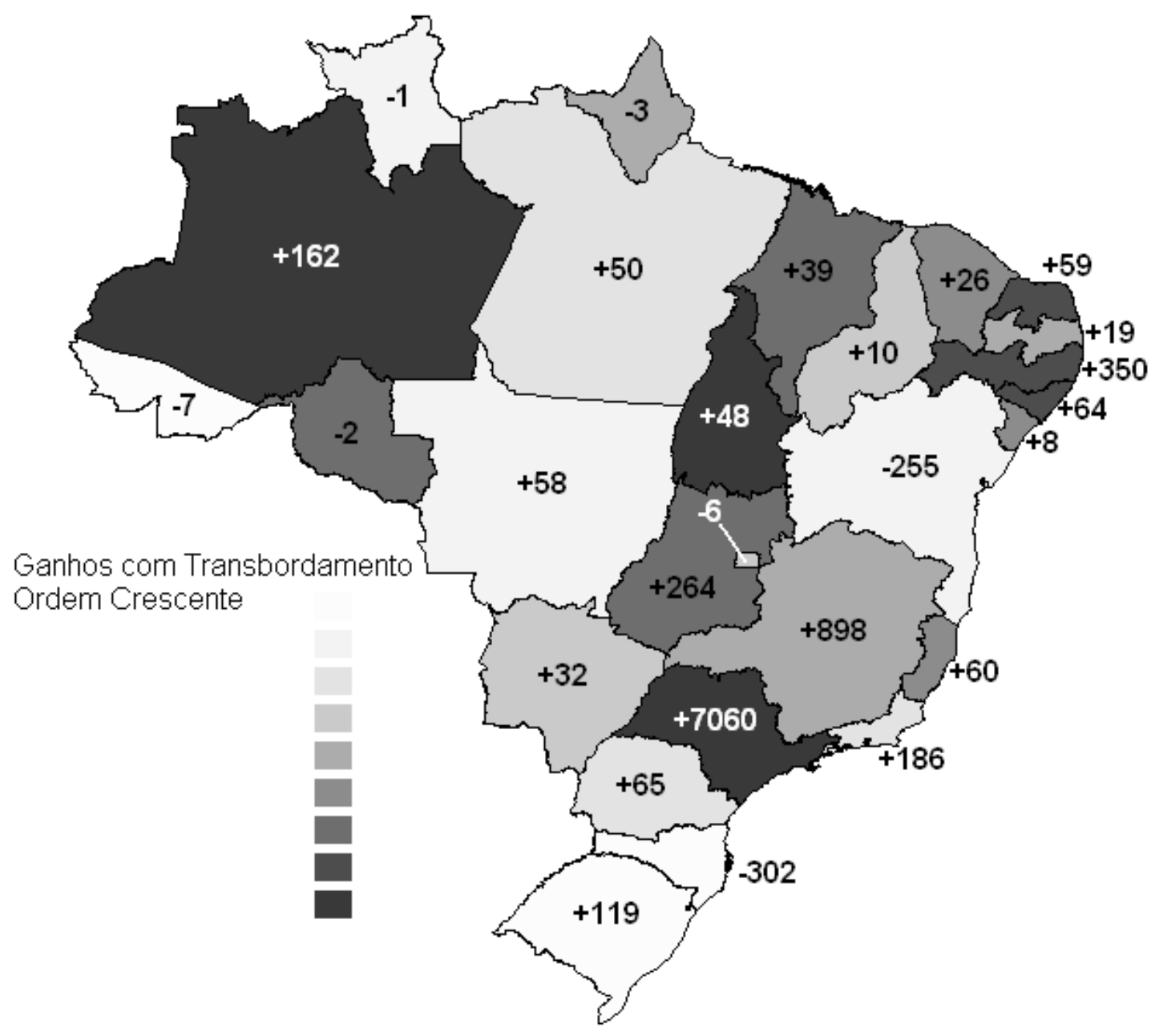



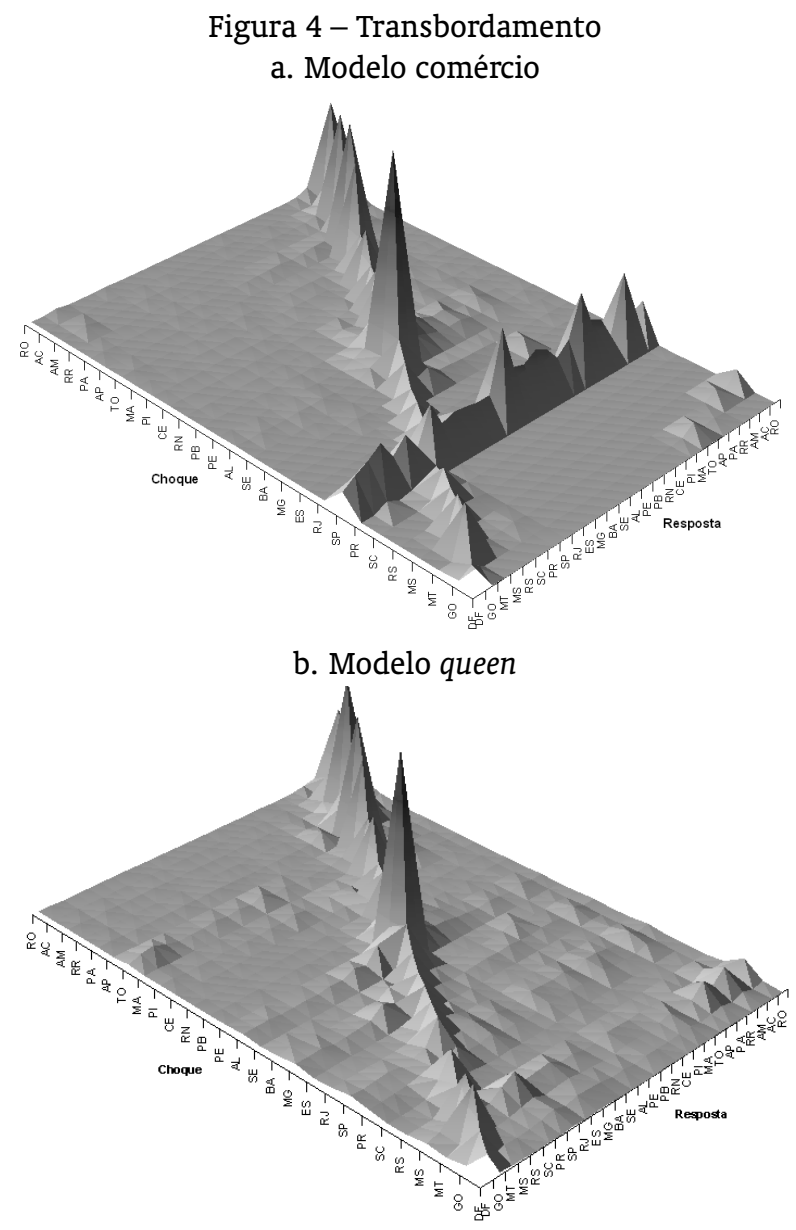

c. Modelo sem transbordamento

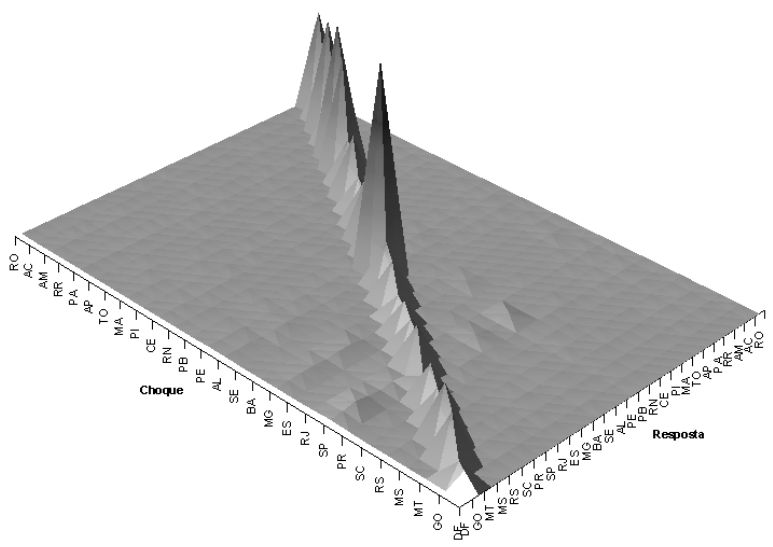

Na Figura 4b, não temos esse efeito da economia paulista devido ao critério de vizinhança da matriz queen, sendo que só se observam pequenos transbordamentos ao longo dos outros estados. Finalmente, na Figura 4c, como esperado, não há transbordamento já que assim se especificou o modelo. Entretanto, um exame cuidadoso da figura, confirmado pelos valores para os choques em Minas Gerais e São Paulo 
revela-se que há um pequeno efeito transbordamento para outras unidades federativas. Isso se explica pela importância dessas economias no contexto inter-regional brasileiro, o que faz com que elas, após o choque monetário, impactem sobre preços, moeda e juros nos períodos seguintes, e dessa forma afetem outros estados.

\section{CONSIDERAÇÕES FINAIS}

A discussão de canais de transmissão da política monetária sobre o lado real da economia sugere que características estruturais das economias regionais são relevantes para explicar os diferentes impactos encontrados entre os estados. Estudos que analisaram os efeitos regionais da política monetária que também tratam desses mecanismos, a exemplo de Fonseca e Vasconcelos (2002) e Carlino e DeFina (1999), enfatizam a importância dos canais de transmissão via juros e crédito. O primeiro adviria do efeito recessivo das restrições de liquidez previsto nos modelos macroeconômicos keynesianos de determinação da renda. O canal do crédito não age de maneira independente do canal dos juros, mas em conjunto, distribuindo sua intensidade pelos setores da economia conforme as condições de mercado prevalecentes. Quando há assimetria de informações e custos de transação, surge a necessidade de um sistema financeiro que aloque as poupanças para os melhores projetos, e diversifique riscos, entre outras de suas inúmeras funções (Terra, 2003, p. 444). Por conta dessas imperfeições, o custo para captar recursos diretamente no mercado de capitais é proibitivo para os negócios menores que acabam tendo de recorrer aos bancos, cuja captação de recursos no mercado financeiro está relacionada às taxas de juros e condições de liquidez influenciadas pela política monetária. Para o caso brasileiro, Terra (2003) mostra que no período entre 1986 e 1997, o padrão de financiamento de firmas pequenas revela menor alavancagem do que firmas grandes. Munido de uma análise econométrica, esse estudo conclui que essas empresas sofrem restrições ao crédito.

Pelas razões de escassez de dados já esclarecidas, optou-se por usar neste trabalho a variável emprego que é altamente correlacionada com atividade econômica. Espera-se que esses canais de transmissão ao afetarem as decisões de investimento, de produção e o desempenho das vendas, impactem sobre uso do fator trabalho na mesma direção. Do ponto de vista de efeitos diretos dos juros sobre a demanda por emprego, Taylor (1983) destaca o papel dos pagamentos de juros sobre capital de giro como custos variáveis da firma em países em desenvolvimento com pobre articulação do sistema financeiro. Isso ressalta a influência da política monetária nas decisões das firmas quanto a contratação de fatores de produção. De maneira geral, os resultados encontrados indicam muitos estados das regiões Norte e Nordeste que são fortemente afetados pelo aumento da taxa de juros. Já são por demais conhecidas as disparidades regionais brasileiras o que, juntamente com a distribuição espacial dos impactos estimados, nos leva a acreditar que condições precárias de acesso a crédito aos setores produtivos desses estados poderiam explicar as assimetrias dos choques.

A principal contribuição deste trabalho foi aplicar a metodologia SVAR de maneira a considerar efeitos espaciais e poder estimar um sistema inter-regional que incorporasse todos os estados brasileiros. Dessa forma, foi possível mostrar a relevância do transbordamento espacial no modelo, o que foi avaliado através de testes estatísticos sobre a especificação de como se daria a propagação espacial dos choques. Uma matriz interestadual construída através do fluxo de comércio foi empregada, o que possibilitou estimar repasses inter-regionais que sob um critério meramente de contigüidade espacial não seriam captados. Desse modo, a persistência da transmissão espacial foi detectada como sendo de menor duração do que quando se utiliza o critério queen (contigüidade). Resumidamente, os impactos se mostraram mais fortes e mais dispersos entre os estados conforme se retira a espacialidade do modelo, o que mostra a importância de se considerar a dimensão têmporo-espacial de propagação de choques macroeconômicos por todo o país. 


\section{Referências Bibliográficas}

Amisano, G. \& Giannini, C. (1997). Topics in Structural VAR Econometrics. Springer, Berlin.

Anselin, L. (1998). Spatial Econometrics: Models and Applications. Kluwer, Dordrecht, The Netherlands.

Araújo, E. (2004). Medindo o impacto regional da política monetária brasileira: Uma comparação entre as regiões nordeste e sul. IBMEC Working Paper 5.

Beenstock, M. \& Felsenstein, D. (2005). Spatial vector auto-regressions. Current working Papers, Department of Economics, Hebrew University of Jerusalem.

Bernanke, B. \& Blinder, A. (1992). The federal funds rate and channels of monetary transmission. American Economic Review, 82(4):901-921.

Bernanke, B. \& Mihov, I. (1998). Measuring monetary policy. Quarterly Journal of Economics, 113(3):869902.

Blanchard, O. J. \& Quah, D. (1989). The dynamic effects of aggregate demand and supply disturbances. American Economic Review, 79(4):655-673.

Carlino, G. \& DeFina, R. (1999). The differential effects of monetary policy: Evidence from US States and Regions. Journal of Regional Science, 39:339-358.

Chumvichitra, P. (2004). Efeitos regionais diferenciados da política monetária: A experiência brasileira. Revista Contemporânea de Economia e Gestão, 2(1):7-22.

De Lucio, J. \& Izquierdo, M. (1999). Local responses to a global monetary policy: The regional structure of financial systems. Documento de Trabajo 99-14. Fundación de Estudios de Economia Aplicada FEDEA.

Di Giacinto, V. (2003). Differential regional effects of monetary policy: A geographical SVAR approach. International Regional Science Review, 26(3):313-341.

Enders, W. (1995). Applied Econometric Time Series. Wiley Series in Probability and Mathematical Statistics. John Wiley \& Sons.

Fonseca, M. \& Vasconcelos, M. (2002). Impactos diferenciados da política monetária nas regiões e estados do Brasil. II Encontro Brasileiro de Estudos Regionais e Urbanos. ABER - Associação Brasileira de Estudos Regionais, São Paulo.

Matsumoto, K. (2000). Efeitos reais da transmissão da política monetária: Comparação empírica entre Brasil e Argentina. Dissertação de mestrado, Escola de Pós-Graduação em Economia, Fundação Getulio Vargas (EPGE/FGV).

Perobelli, F. S. \& Haddad, E. A. (2006). Padrões de comércio interestadual no Brasil, 1985 e 1997. Revista de Economia Contemporânea, 10(1):61-88.

Sims, C. A. (1980). Macroeconomics and reality. Econometrica, 48(1):1-47.

Taylor, L. (1983). Structuralist Macroeconomics. Basic Books, Inc., New York.

Terra, M. C. (2003). Credit constraints in Brazilian firms: Evidence from panel data. Revista Brasileira de Economia, 57(2):443-444.

Vasconcellos, M. A. S. \& Alves, D. C. O. (1999). Manual de Econometria: Nível Intermediário. Atlas, São Paulo. 
Vasconcelos, J. R. \& Oliveira, M. A. (2006). Análise da matriz por atividade econômica do comércio interestadual no Brasil (1999). Textos para Discussão do IPEA 1159, Rio de Janeiro.

Von Hagen, J. \& Waller, C. J. (2000). Regional aspects of monetary policy in Europe. In ZEI Studies in European Economics and Law. Kluwer, Dordrecht, The Netherlands. 


\section{APÊNDICE}

\section{Modelo SVAR}

A especificação SVAR, conhecida como modelo AB, descrito em Amisano e Giannini (1997), pode ser assim expressa:

$$
\begin{aligned}
& A_{0} \cdot y_{t}=A_{1} \cdot y_{t-1}+\cdots+A_{p} \cdot y_{t-p}+A_{0} \cdot u_{t} \\
& A_{0} \cdot u_{t}=B \cdot \epsilon_{t} \\
& E\left[\epsilon_{t} \cdot \epsilon_{t}^{\prime}\right]=I_{n}
\end{aligned}
$$

O vetor $\epsilon_{t}$ representa os erros estruturais das equações, os quais são não correlacionados no tempo e entre equações, e possuem variância unitária (matriz variância-covariância identidade). Nesta especificação é possível estabelecer relações contemporâneas entre as variáveis (matriz $A_{0}$ ) bem como entre os erros estruturais e os da forma reduzida através da matriz $B$. Pode-se escrever a matriz variânciacovariância dos erros na forma reduzida $\left(\sum\right)$ em termos da matriz $A_{0}$ e $B$ :

$$
\begin{aligned}
& A_{0} \cdot u_{t} \cdot u_{t}^{\prime} \cdot A_{0}^{\prime}=B \cdot \epsilon_{t} \cdot \epsilon_{t}^{\prime} \cdot B^{\prime} \\
& u_{t} \cdot u_{t}^{\prime}=A_{0}^{-1} \cdot B \cdot \epsilon_{t} \cdot \epsilon_{t}^{\prime} \cdot B^{\prime} \cdot\left(A_{0}^{\prime}\right)^{-1} \\
& \Sigma=E\left[u_{t} \cdot u_{t}^{\prime}\right]=A_{0}^{-1} \cdot B \cdot B^{\prime} \cdot\left(A_{0}^{\prime}\right)^{-1}
\end{aligned}
$$

A matriz $\sum$ é simétrica e por isso dela temos $n(n+1) / 2$ elementos distintos. As matrizes $A_{0}$ e $B$ possuem $n^{2}$ elementos cada. Assim, supondo que se conhece a matriz $\sum$, a igualdade acima impõe $n(n+1) / 2$ restrições não-lineares para obter os $2 n^{2}$ elementos de $A_{0}$ e $B$. Uma condição necessária para identificá-los é que se imponha $2 n^{2}-n(n+1) / 2$ restrições sobre esses parâmetros. Quando se tem esse número exato de restrições e as condições suficientes ${ }^{10}$ são satisfeitas, diz-se que o sistema é exatamente identificado bastando resolver a igualdade para obter as estimativas para as matrizes $A_{0}$ e $B$. Entretanto, caso alguma fundamentação teórica sugira mais restrições do que o necessário, ter-se-á um modelo sobre-identificado. Seguindo Amisano e Giannini (1997), utiliza-se o método de estimação por máxima verossimilhança FIML (Full Information Maximum Likelihood) para obter os valores dos mesmos coeficientes. As estimativas das matrizes $A_{0}$ e $B$, bem como das FRI, foram obtidas utilizando rotinas para WinRATS, disponibilizadas no site: www.estima.com.

\section{Funções resposta a impulso}

A seguir estão os gráficos das FRI, valores acumulados para o período de 6 meses, para a taxa de variação mensal do emprego em cada estado como resposta ao impulso na taxa SELIC no primeiro período (linha preta). Os intervalos de confiança foram calculados com significância de $10 \%$. O modo como os estados estão dispostos segue a mesma ordem da Tabela 4.

\footnotetext{
${ }^{10}$ Não se aborda aqui a condição suficiente para identificação: ver Amisano e Giannini (1997, p. 56).
} 
Tocatins
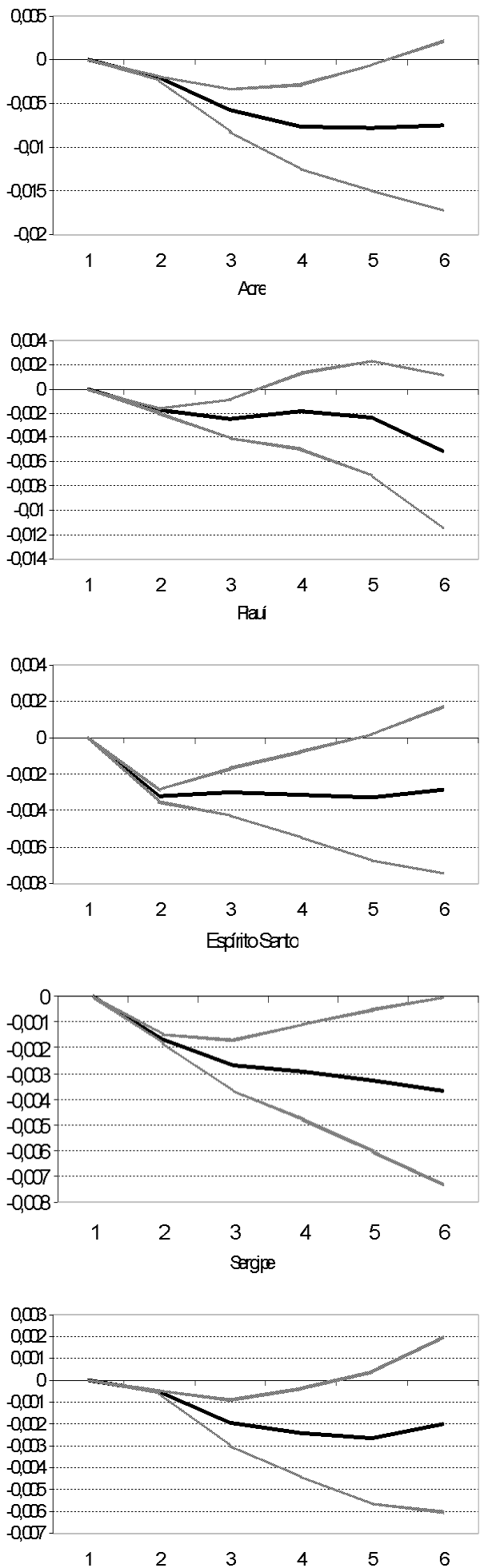

Anzán
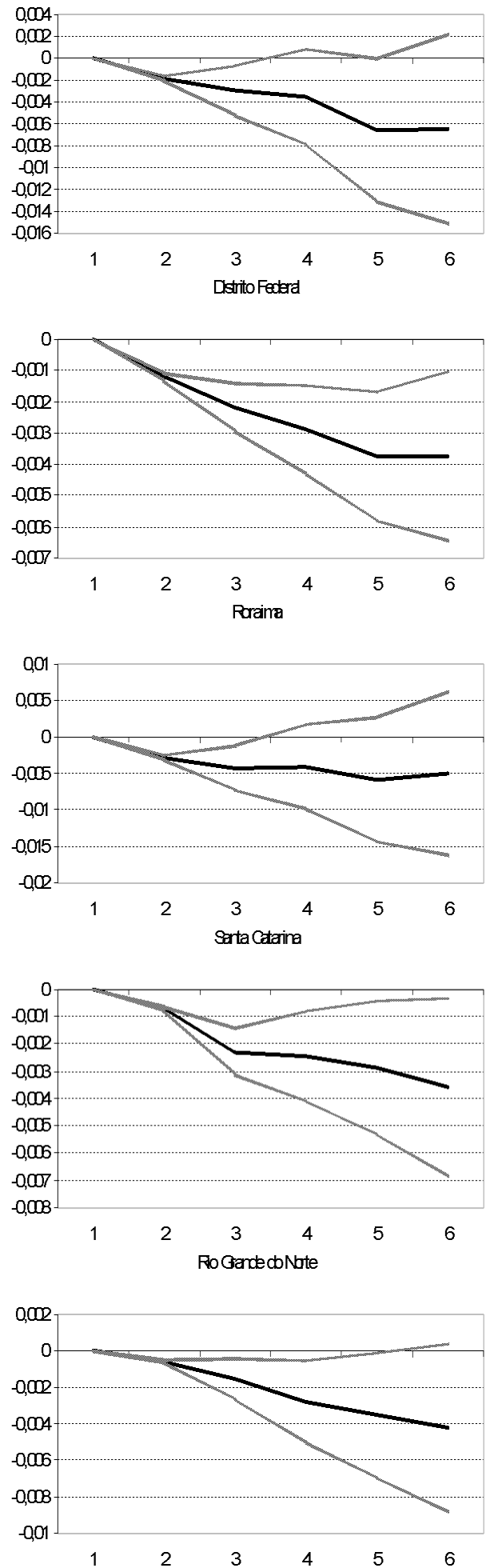

RBE Rio de Janeiro v. 62 n. 1/ p. 3-29 Jan-Mar 2008 
Anzones
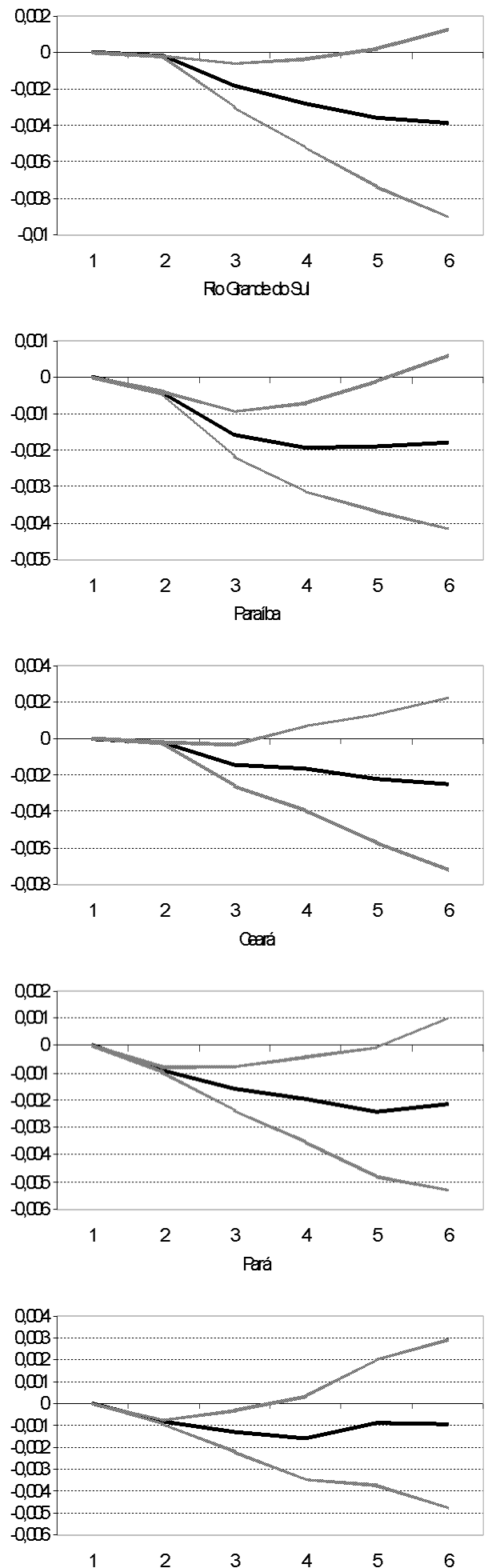

Baria
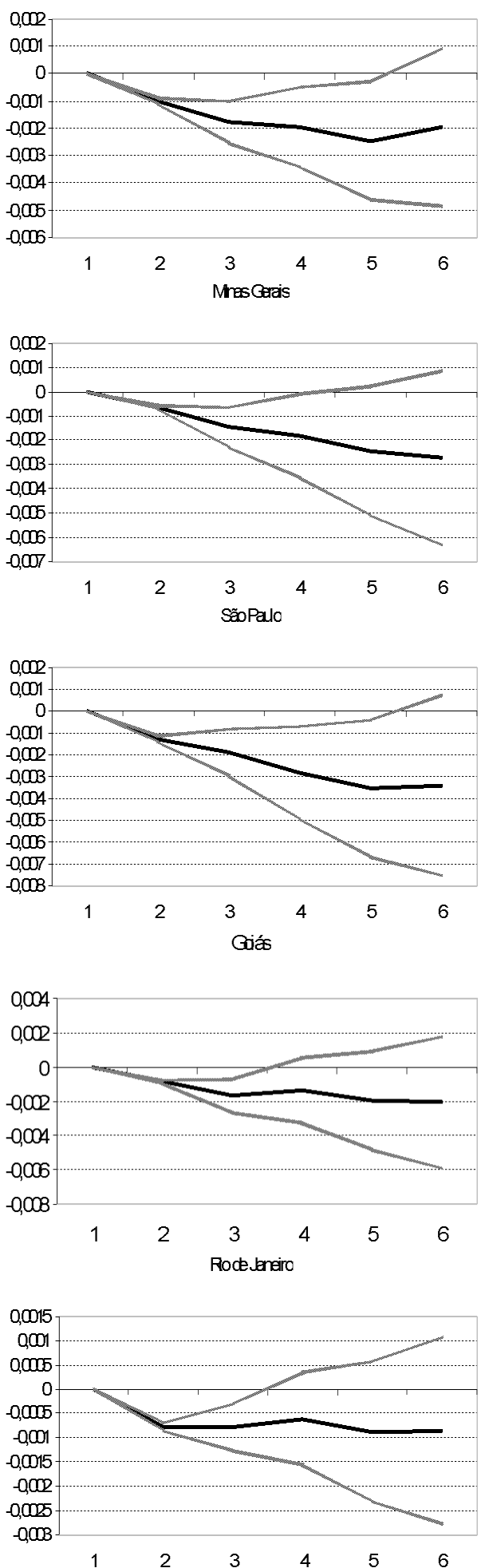
NatoGosso
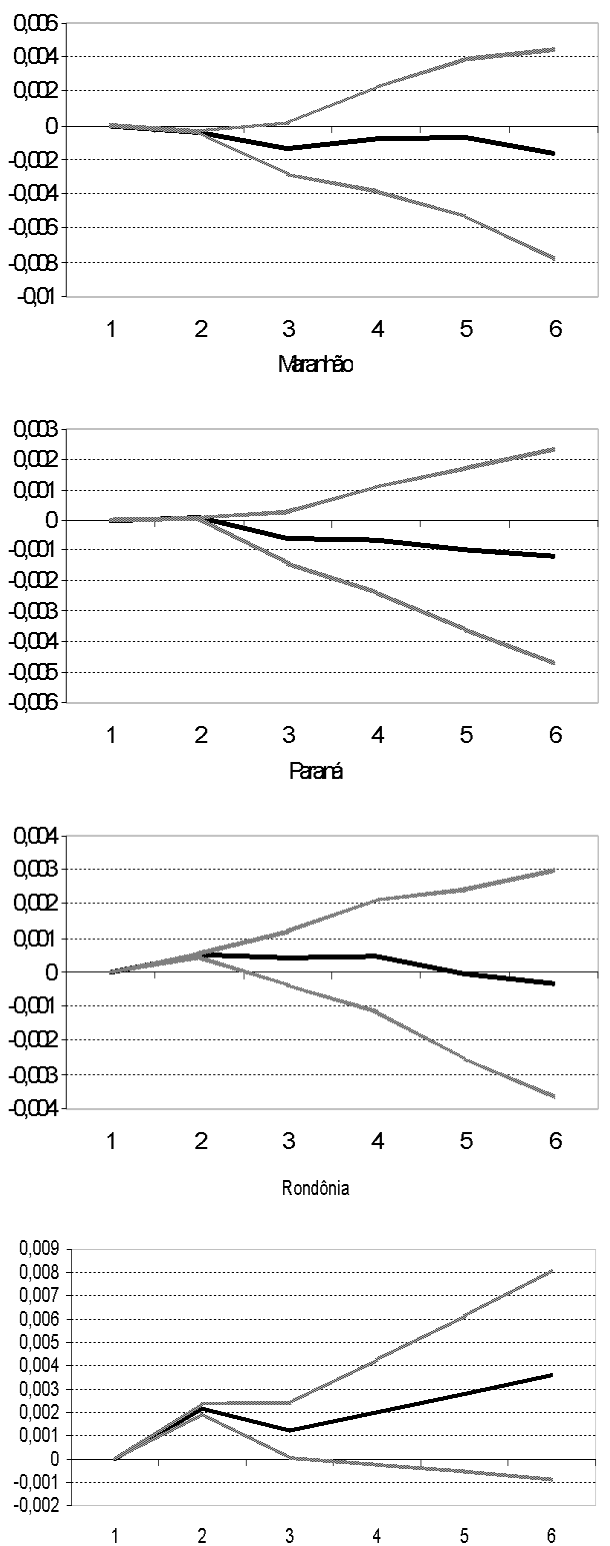

Nato Gossodb
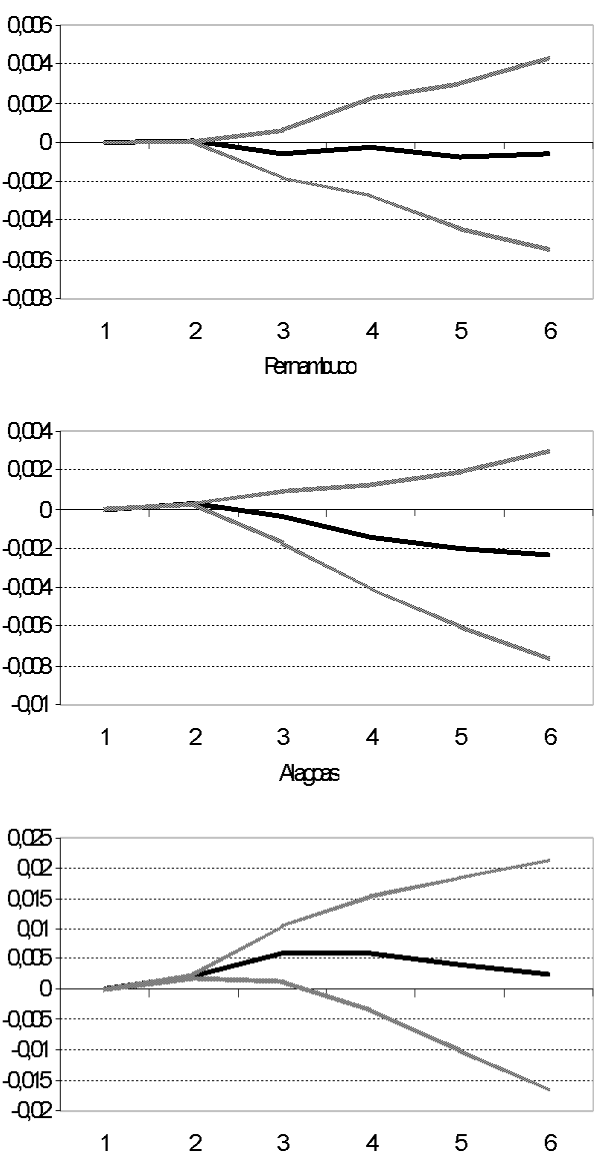